\title{
Understanding Country Level Adoption of E-Commerce:
}

\section{A Theoretical Model Including Technological, Institutional, and Cultural Factors}

\author{
Punit Ahluwalia, University of Texas Rio Grande Valley, Edinburg, USA \\ Mohammad I. Merhi, Indiana University South Bend, South Bend, USA
}

\begin{abstract}
This paper provides a theoretically grounded model of e-commerce adoption to explain differences in adoption rates among countries. The model extends the existing culture-policy-technology (CPT) framework to examine causal relationships between the technological, institutional, and cultural factors in order to examine country-level e-commerce adoption. Thus, interesting relationships among macrolevel factors are hypothesized. The paper highlights the important of risk mitigating mechanisms or institutions to facilitate adoption of e-commerce in countries with high uncertainty avoidance. A call for empirical examination into country level adoption is answered by analyzing macro level data from 69 countries. The hypotheses are confirmed using PLS analytical procedures. The study is timely as e-commerce technology has now taken hold in several countries but its revenues in proportion to the overall total revenues remain low. The study is motivated by significant different in e-commerce adoption rates among countries. The paper makes significant contributions to literature and practice.
\end{abstract}

\section{KEYWORDS}

Country Environment, Cross-Country Studies, E-Commerce Adoption, Efficacy of Institutional Safety-Net, Government Policy, Maturity and Reach of Internet Technologies, Uncertainty Avoidance

\section{INTRODUCTION}

In an ICT (Internet and Communication Technologies) enabled interdependent world, most countries consider e-commerce as a significant instrument for economic growth (Merhi \& Ahluwalia, 2018; Zhu \& Thatcher, 2010). However, despite early promise, overall e-commerce revenues remain insignificant in comparison to the overall business volumes (D'Onfro, 2015; Edquid, 2017) and e-commerce adoption at the global level remains low (Commission, 2011; EUR, 2013; Postnord, 2014; Stambor, 2010). Research shows that e-commerce adoption rates among different countries and regions exhibit significant variations (Zhu \& Thatcher, 2010; Statista, 2017). For example, in 2017 e-commerce sales accounted for only $2.2 \%$ of the total retail sales in India, $23.1 \%$ in China, and $16 \%$ in Korea (Statista, 2017). Disparities exist even within the same continent or the same group of nations (developed vs. emerging). For example, in Europe, online shoppers in the age group between 15 and 79 ranged from less than $40 \%$ in Italy to more than $80 \%$ in United Kingdom (Postnord, 2014). Statista (2017) reported that in 2017 the share of e-commerce sales in the total retail sales is $19.1 \%$ in UK, $12.6 \%$ in Denmark, and 7.9\% in Germany. According to a study by Business.com in 2017,

\section{DOI: 10.4018/JGIM.2020010101}

This article, originally published under IGI Global's copyright on October 4, 2019 will proceed with publication as an Open Access article starting on January 11, 2021 in the gold Open Access journal, Journal of Global Information Management (converted to gold Open Access January 1, 2021), and will be distributed under the terms of the Creative Commons Attribution License (http://creativecommons.org/licenses/ by/4.0/) which permits unrestricted use, distribution, and production in any medium, provided the author of the original work and original publication source are properly credited. 
the e-commerce share of total retail sales in Japan 5.4\%, France 5.1\%, Canada 5.7\%, Russia 2\%, and Brazil 2.8\% (Edquid, 2017). The question then arises, "what causes such variations?" Additionally, because of gradual and consistent accretion in e-commerce trade volumes in recent times, governments across the nation states are focused on improving their share in the overall global trade. Therefore, it is important to examine the important drivers of e-commerce adoption at a country level.

In the existing literature, studies focusing on macro-level determinants of e-commerce adoption are few; most of this research mainly emphasizes individual and organizational environments (Delone \& Mclean, 2004; Grandon et al., 2011; Chiu et al., 2014). Although individual and firm level factors are important, they do not explain significant differences in e-commerce adoption among countries. Moreover, because of sampling constraints, the generalization of the results reported in the existing research that examine macro-level determinants of e-commerce adoption is rather limited. Most existing studies focus on adoption factors within one country (Stylianou et al., 2003; Yoon, 2009; Al-Hudhaif \& Alkubeyyer, 2011; Jehangir et al., 2011). Also, a significant number of these studies are based on qualitative methodology (Aleid et al., 2009; Choudrie \& Dwivedi, 2005). As a result, Tan et al. (2007) called for empirical research into cross-cultural and cross-country analysis of e-commerce adoption factors.

Moreover, most existing research examining e-commerce adoption by higher-order entities is exploratory and is not theoretically grounded, the only exceptions being Molla and Licker (2005b). They proposed the perceived e-readiness model based on the interactionism doctrine; but this model is targeted for organizations, not countries (Molla \& Licker 2005b). Bajaj and Leonard (2004) proposed the CPT model targeted toward country-level e-commerce adoption in which they identified Culture, Policy, and Technology as the main first-order drivers underlying adoption. This paper draws from the CPT framework (Bajaj \& Leonard, 2004) to propose a causal model that includes technological, institutional, and cultural factors as antecedents of e-commerce adoption. In doing so, we introduce increasingly pertinent factors (e.g. perceived efficacy of safety nets as an antecedent of e-commerce adoption) and drop factors that have become irrelevant (e.g. hard-wired vs wireless Internet). The present paper draws from the CPT framework yet significantly extends its propositions. With the passage of nearly 15 years since the CPT framework was initially published, there have been radical changes in the Internet and e-commerce milieu. With significant evolution in the quality, availability, and accessibility of wireless Internet as well as very high level of diffusion of wireless Internet, the userperceptible differences between wireless and hard-wired Internet access have virtually disappeared. For example, the CPT framework considers hard-wired Internet and wireless Internet as separate technological factors. Additionally, the CPT model advances propositions based on logical arguments. This paper significantly advances the research of Bajaj and Leonard (2004) by grounding the present research in established theories. Even though building upon the CPT framework, this research does not very strictly associate each of the factors included in the research model in a higher order factor. For example, the PEISN factor presented in the paper may be described as a cultural factor but also has significant policy implications. Yet another distinction between the CPT model and the research model presented in this paper is that we do not claim that our model provides comprehensive explanation of e-commerce adoption by countries. Unlike in Bajaj and Leonard (2004), we investigate a causal model to investigate the relationships among various factors of interest.

Now, we briefly introduce the factors included in our model, but expand their discussion in the subsequent sections of the paper. The technology drivers are captured in the composite index called "Maturity and Reach of Internet Technologies (MRIT)." MRIT includes dimensions such as accessibility, adequate bandwidth, diffusion of mobile networks, and implementation of security protocols. Research shows that governments are the primary agents for devising and implementing policies and creating channels for investments towards implementation of IT infrastructure (Picot \& Wernick, 2007; Stoica et al., 2005); thus, government's focus on IT is a key driver of MRIT. Based on the Theory of Planned Behavior (TPB) and the Social Cognitive theory (Bandura, 1986), we argue that the perceived efficacy in using technology is an important driver of e-commerce adoption. We 
call this index "technological and entrepreneurial efficacy (TEE)." In order to mitigate the effect of uncertainty avoidance, institutional safety nets can safeguard the risks faced by the more vulnerable of the transacting parties. We also examine the role of perceived efficacy of institutional safety nets (PEISN) in facilitating adoption of e-commerce by people. To the best of our knowledge, this is the first paper that inquires into the effect of TEE, PEISN and uncertainty avoidance on country level adoption of e-commerce.

This paper makes significant contributions to research and practice. First, it contributes to the literature by examining the socio-technical determinants of country-level e-commerce adoption by developing a theoretically grounded research model that includes macro-level antecedents of e-commerce adoption. Second, this is the first paper that examines the role of safety nets as risk mitigating entities in e-commerce adoption. Third, the findings of this paper contribute to practice by suggesting the type and level of relationships of various factors of interest with e-commerce adoption. Fourth, the authors answer Tan et al. (2007)'s call for research by generating a significantly robust sampling frame comprising of sixty-nine countries in order to improve the generalizability of the findings reported in this paper. We make novel use of country-level data published by reputable organizations. The GFIT, MRIT, TEE, and e-commerce adoption indexes were published in the digital economy ranking study conducted by EIU (EIU, 2010). The PEISN data is sourced from the World Economic Forum (https://www.weforum.org/reports).

The paper answers the following research questions:

a) What are the relevant antecedents of e-commerce adoption at the country level in technological, social, and institutional domains?

b) What are the inter-relationships between various factors and country level e-commerce adoption?

The remainder of this paper is organized as follows. Section 2 provides background of the existing literature and the concepts examined in this paper. Section 3 describes the theoretical underpinnings of the research model and postulates different hypotheses examined in the paper. Section 4 provides information about the data used for empirical analysis. In section 5, the results are presented, and their implications are discussed. Lastly, section 6 concludes the paper by summarizing its important findings, highlighting its contributions, noting its limitations, and identifying opportunities for future research.

\section{BACKGROUND}

The units of analysis of most e-commerce adoption research are consumers and businesses. Kalakota and Whinston (1996) focus on consumers as they define e-commerce as "the delivery of information, products/services, or payments via telephone lines, computer networks or any other means." Zwass (1996) provides an organizational context to e-commerce by describing it as "the sharing of business information, maintaining business relationships, and conducting business transactions by means of telecommunications networks." Treese and Stewart (1998) define e-commerce more generally by stating that it is the "use of the global Internet for purchase and sale of goods and services, including services and support after the sale." While scholars have abundantly explored the individual and organizational perspectives, theory-based research into country level e-commerce adoption remains scarce. This paper attempts to bridge this gap in the current literature.

The e-commerce revenues continue to grow across the world because of explosion of Internet adoption (EMarketer, 2016). The development of reliable and advanced $\mathrm{m}$-commerce technologies and the exponential increase in the use of smart devices is fueling this growth even more. Yet, the total e-commerce retail sales were a meager $7.4 \%$ ( $\$ 1.671$ trillion) of the total worldwide retail sales of \$22 million (EMarketer, 2016).

Considering that e-commerce offers many benefits, the ratio of e-commerce sales to the total sales is likely to continue to increase in the coming years. Because of the widespread diffusion of the 
Internet, and unlimited availability of information to consumers, electronic markets are considered more efficient than the traditional markets (Calabrese et al., 2014; Blažic et al., 2015; Cui et al., 2015; Ghose \& Yao, 2011; Wang et al., 2015). Consumers can purchase products without having to travel to the stores, saving them time and money; moreover, they have access to a wider selection of products. A comparison between $\mathrm{B} 2 \mathrm{C}$ e-commerce and brick and mortar shopping reveals various convenience advantages associated with e-shopping; namely search convenience defined as "products easy to find and compare" (Kaufman-Scarborough \& Lindquist, 2002), possession convenience, time convenience, and schedule convenience (Pavlou \& Gefen, 2004). E-retail provides consumers with enhanced services; namely the ability to research and compare products, expanded choice in products, and ability to transact anytime-anywhere (Wu \& Tsai, 2018). As the search costs are trivial and there is no restriction of geographical product differentiation, mass-produced physical goods are expected to exhibit none or at most minimal price differentiation, making electronic markets attractive to the consumers (Luo et al., 2007). According to one estimate, the year on year growth in e-commerce retail sales was nearly 25\% in 2015 (EMarketer, 2016). Organizations tracking e-commerce sales have also reported significant diversity in growth rates among different countries: examples being 22.3\% in Argentina, 12.2\% in China, and 3.7\% in USA (EMarketer, 2016). These studies have also reported significant diversity in percentage retail e-commerce sales in different countries. Table 1 shows the annual sales and the e-commerce share of total retail sales in year 2016 (Edquid, 2017).

Even though some researchers have looked into the causes of between-country divergences in adoption of e-commerce, there is a lack of theory-based empirical research that examines the relationships among the factors underlying such divergences. Tan et al. (2007) gave a call for research to examine inter-cultural and inter-country differences in e-commerce adoption. Most studies that examined country-level adoption of e-commerce are case studies based on data from single countries. Many of these are based on qualitative analysis of interview data. Nevertheless, these research studies are valuable because they illuminate significant drivers of country level e-commerce adoption. A succinct review of this literature is provided next.

Examples of studies focusing on e-commerce adoption in one country are: Saudi Arabia (AlHudhaif \& Alkubeyyer, 2011), France (Brousseau, 2003), Taiwan (Chen \& Barnes, 2007), China (Stylianou et al., 2003; Yoon, 2009), India (Vyas \& Gupta, 2017) and Singapore (Wong, 2003). Some studies compared two or more countries as case studies: examples being USA and Saudi Arabia (Brosdahl \& Almousa, 2013); USA and China (Tong, 2010); South Africa and Sub-Saharan countries (Molla \& Licker, 2005b) and USA and Canada (Hong \& Zhu, 2006).

Table 1. E-commerce sales as a percentage of total sales in 2016 (Edquid, 2016)

\begin{tabular}{|l|l|l|}
\hline \multicolumn{1}{|c|}{ Country } & \multicolumn{1}{|c|}{ Annual online sales } & \multicolumn{1}{c|}{$\begin{array}{c}\text { E-commerce share of total retail } \\
\text { sales }\end{array}$} \\
\hline China & $\$ 672$ billion & $15.9 \%$ \\
\hline U.S. & $\$ 340$ billion & $7.5 \%$ \\
\hline U.K. & $\$ 99$ billion & $14.5 \%$ \\
\hline Japan & $\$ 79$ billion & $5.4 \%$ \\
\hline Germany & $\$ 73$ billion & $8.4 \%$ \\
\hline France & $\$ 43$ billion & $5.1 \%$ \\
\hline South Korea & $\$ 37$ billion & $9.8 \%$ \\
\hline Canada & $\$ 30$ billion & $5.7 \%$ \\
\hline Russia & $\$ 20$ billion & $2 \%$ \\
\hline Brazil & \$19 billion & $2.8 \%$ \\
\hline
\end{tabular}


Wong (2003) found that demographic structure, financial and legal institutions, physical infrastructure, human resources, and e-commerce policy initiatives impacted the adoption of e-commerce in Singapore. Molla and Licker (2005b) indicated that perceived organizational e-readiness (POER) and perceived environmental e-readiness (PEER) influenced e-commerce adoption in South Africa. Ho et al. (2007) found that Internet penetration, telecommunication investment intensity, educational level, and regional contagion affected e-commerce adoption in 17 European countries. Government policies, supportive legal environment, compatible socio-cultural infrastructure, ICT infrastructure, and culture differences also affect e-commerce adoption (Ferguson \& Yen, 2006; Javalgi \& Ramsey, 2001; Merhi \& Ahluwalia, 2018; Zhu \& Thatcher, 2010). Merhi and Ahluwalia $(2015,2016)$ argue that Internet connectivity, social and cultural environment and legal environment influenced e-commerce adoption at the country level.

Papazafeiropoulou (2004) examined e-commerce adoption in South European countries using the demand-pull and supply-push framework and made policy recommendations for better diffusion of technology in this region. Tan et al. (2007) examined organizational e-commerce adoption in China by using a perceived eReadiness Model framework earlier proposed by Molla and Licker (2005b). Although the study focused on organizational adoption, the eReadiness model includes external (to the organizations) factors such as Government eReadiness, Market Forces eReadiness, and Support Industries eReadiness. These factors are also relevant to country-level examination of the diffusion process. Tan et al. (2007) acknowledged that their study was conducted in one of the most advanced regions of China and gave a call for large, cross-cultural and cross country examination of the e-readiness model. Aleid et al. (2009) investigated the factors that influenced consumers' e-commerce adoption in Saudi Arabia. Based on the analysis of interview data, they reported availability, cost, and speed of broadband; the business process of delivery and returns; information about terms and conditions; security concerns; legal framework; government responsibility; and people's education as the important factors that affected e-commerce adoption in the country. Consumer trust, awareness of technology, technological infrastructure, e-maturity, education, and government policies have been identified as pertinent macro-level factors underlying e-commerce adoption (Mahmood et al., 2004; Pavlou \& Gefen, 2004; Rose \& Straub, 2001).

Most literature examining country-level e-commerce adoption comprises of exploratory studies, therefore they do not provide a cogent model or framework that could be applied in subsequent research. The first theoretically grounded model, named perceived eReadiness model (PERM), was proposed by Molla and Licker (2005b) which classified various pertinent factors of e-commerce adoption into organization and external factors. This eReadiness model presupposes the context as innovation adoption by organizations. The present study looks at the e-commerce adoption at a more general level and is not restricted to the organizational context. However, the theoretical reasoning underlying the PERM model can well be applied to the focus of the inquiry of this paper (Molla \& Licker, 2005b). Particularly relevant is the interactionism doctrine which argues for collective treatment of multiple imperatives, that is, technology, managerial, organization, and environmental imperatives, in one framework. A framework focused on country-level adoption of e-commerce at a macro-level, and not constrained by the organizational context, is the Culture, Policy, and Technology (CPT) framework (Bajaj \& Leonard, 2004). The CPT framework is not as explicitly grounded in theory as the PERM model ${ }^{1}$, but is similar to the latter, except that it is focused on macro-level factors of adoption. The culture construct in the CPT framework identifies the dimensions of trust, corruption, and the patterns of communication. The policy factor includes the dimensions focused on general trade and on Internet usage and e-commerce. The technology factor comprises of three dimensions, namely, maturity of hard-wired telecommunication infrastructure, technical expertise within a country, and the level of wireless infrastructure.

We draw from the CPT model (Bajaj \& Leonard, 2004) to frame the research model of the present study. Some changes in the CPT model may be necessary because of the evolution of different factors with the passage of time. For example, the wireless networks, devices, and applications have made 
quantum leaps in capability and diffusion from the time when the model was published. In the present times, users feel little difference in the reliability and bandwidth of Internet connections when using hard-wired or mobile Internet. Therefore, it may not be necessary to distinguish between hard wired networks and wireless networks in the context of e-commerce adoption as was conceptualized in the CPT framework. In this paper, we examine the impacts of two technological constructs, MRIT and TEE. As numerous articles reported the key role of government in implementation of IT infrastructure, we include Government Focus on IT (GFIT) in our model. Also, several articles emphasize that culture is a key factor why the adoption rates vary among countries. In particular, the exploratory studies that examined e-commerce adoption in developing countries highlight uncertainty and risk as significant concerns in the minds of potential adopters of e-commerce, especially in developing countries. Therefore, the role of uncertainty avoidance and perceived efficacy of institutional safety nets in affecting country-level e-commerce adoption is worthy of a rigorous investigation.

In e-commerce literature, researchers have only chosen, out of all other cultural dimensions of Hofstede, to examine the impact of uncertainty avoidance on e-commerce adoption. These studies have examined the influence of uncertainty avoidance based on primary data collected from individuals of certain countries. Belkhamza and Wafa (2014) examined the impact of uncertainty avoidance on e-commerce adoption using data collected from Malaysia and Algeria. They found that uncertainty avoidance moderates the relationships between perceived usefulness, subjective norm, attitude, and intention to use e-commerce. In a study that investigated the impact of uncertainty avoidance and perceived risk on e-commerce in USA, Jordan, and India, Al Kailani and Kumar (2011) found that uncertainty avoidance and perceived risk negatively impact e-commerce adoption. Karahanna et al. (2013) collected data from 3500 consumers from 38 countries and found that uncertainty avoidance moderates the relationships between information quality and perceived usefulness, and between trust and e-loyalty.

Although these studies are important, they lack generalizability. We argue that in order to examine the impact of cultural impact on a phenomenon, country level data are required. For this reason, we investigate the impact of uncertainty avoidance on e-commerce adoption using Hofstede index.

Therefore, we include uncertainty avoidance in the research model of the present study. Finally, we borrow from the safety-net literature to posit perceived efficacy of institutional safety nets (PEISN) as an important determinant of e-commerce adoption. PEISN is an important factor especially in cultures where people associate greater risk with usage of e-commerce and presence of safety nets can instill the necessary confidence in people.

\section{RESEARCH MODEL AND HYPOTHESES}

This section explains the theoretical reasoning underlying different hypotheses examined in the present paper.

\subsection{Government's Focus on IT and Maturity and Reach of Internet Technologies}

The stakeholder theory provides a lens through which government's role in technology diffusion can be examined; political and economic philosophies and culture being other important factors. Governments' eminent role in diffusion of new technologies is widely reported in the literature (Papazafeiropoulou \& Pouloudi, 2000). Japan and countries in Europe and North America designed and implemented technology policies dating back to 1970s (Papazafeiropoulou \& Pouloudi, 2000). Freeman and Reed (1983) in their initial explication of stakeholder theory espoused the argument that organizations need to meet their goals by "balancing the conflicting claims" of its various stakeholders. The term stakeholder has been defined in several ways in the literature, ranging from a very restrictive to a very expansive view. The stakeholder theory changes the paradigm of organizational governance by shifting the focus from stockholders to stakeholders. Government's role in promoting technology and innovation can be classified into three technology policy paradigms, namely; market failure, 
mission mode, and cooperative paradigms. The "Market Failure" paradigm propounds that private markets are the best places for technology innovation, and the role of the government is restricted in the areas of defense and in times of market failure. The "mission mode" paradigm asserts a more participatory role of the government in which it acts as a complementary agent to the private sector by participating through grants and funding of universities and R\&D organizations; the government does not compete with the private sector in this paradigm. In the "cooperative paradigm," governments can participate in technology development and innovation, especially for use of private sector (Bozeman, 2000). This framework explains different strategies adopted by different governments in promoting IT infrastructure in their respective countries.

Digital economy has become a significant contributor to the overall economic well-being of countries. In an increasingly interconnected world, countries are constantly competing with each other in order to increase their share in global trade and commerce. With digital economy becoming an increasingly significant platform for conducting trade and commerce, it is natural that governments would focus their attention and resources on putting in place adequate supporting ICT infrastructure in order to augment the access and quality of information technologies. In their study of diffusion of e-commerce in southeastern European countries, Papazafeiropoulou (2004) found that all governments supported the use of Internet and e-commerce.

Furthermore, governments are providers of efficient and unmediated services to its citizens through digital applications using ICT platforms. E-government applications have yielded expanded reach, faster speeds, and greater effectiveness in providing essential services to citizens (Merhi \& Koong, 2013). As keepers of public interest, responsible governments are obliged to pay attention to reducing digital divide and to provide a fair technological platform for private sector to participate and compete. IT products and services now contribute significantly to the national assets of many countries. Research shows that governments make efforts to digitize the public sector not only to organize them better and make them more efficient, but also to offer indirect benefits by disseminating best practices to the industry and making people familiar with the technologies (Chen et al., 2006; Papazafeiropoulou, 2004). Thus:

Hypothesis 1: Government's greater focus on IT (GFIT) is positively related to, and is an antecedent of, the maturity and reach of Internet technologies (MRIT).

\subsection{Maturity and Reach of Internet Technologies (MRIT), Technological and Entrepreneurial Efficacy (TEE) and E-Commerce Adoption}

Implementation of an robust and reliable ICT infrastructure is an essential driver of e-commerce adoption (Okoli et al., 2010; Zwick \& Dholakia, 2008, Mbarika et al., 2005). Similarly, the lack of telecommunication infrastructure is known to act as a barrier in the growth of e-commerce adoption (Kaba et al., 2009). Research shows that e-commerce depends on quality and effectiveness of Internet and mobile phone communications (Zwick \& Dholakia, 2008) and computers (Elen et al., 2010). Higher broadband penetration, low prices of internet access, and good quality of network connections are likely to facilitate e-commerce adoption. Stylianou et al. (2003) found that even though the business climate in China was conducive to e-commerce adoption, it was hindered by inadequate technological infrastructure. Thus, ubiquitous availability of Internet access, reliable network connections, affordable prices, and implementation of adequate security protocols in the network and web technologies are fundamental drivers of e-commerce adoption. Thus:

Hypothesis 2: Maturity and reach of Internet technologies (MRIT) is positively related to, and is an antecedent of, e-commerce adoption. 
Self-efficacy is defined as the belief "in one's capabilities to organize and execute the courses of action required to produce given attainments" (Bandura, 1997). According to social cognitive theory (Bandura, 1986, 1997), self-efficacy is considered as a form of self-evaluation that affects individuals' decisions about what behaviors to undertake, the amount of effort needed when faced with obstacles, and the mastery of their behavior. Therefore, individuals having low levels of self-efficacy are less likely to perform a related behavior in the future than those with high degree of self-efficacy (Bandura, 1997). The IS literature has affirmed the importance of IT self-efficacy in adopting e-commerce (Bhattacherjee, 2000; Hsu \& Chiu, 2004). These studies show that higher IT self-efficacy leads to greater e-commerce adoption. Molla and Licker (2005a) suggest technological preparedness and capability of organizations to adopt e-commerce. Aleid et al. (2009) suggested that people's education about e-commerce and lack of specialized IT companies and professionals were significant factors affecting e-commerce adoption in Saudi Arabia. Similar findings were reported in the investigation of e-commerce adoption by small and medium enterprises in Indonesia (Govindaraju \& Chandra, 2011). They reported that number of educated people and people with IT skills, knowledge about the benefits of e-commerce, and the organization's way of doing business restricted the adoption. The foregoing explanation leads to the third hypothesis of this study:

Hypothesis 3: Technological and entrepreneurial efficacy (TEE) is positively related to, and is an antecedent of e-commerce adoption.

Gist and Mitchell (1992) suggest that analysis of task requirements, attributional analysis of experience, and assessment of personal and situational resources/constraints are the three important determinants of self-efficacy. The analysis of task requirements involves inferences about personal skills or qualities to perform an action. Attributional analysis is more about past experiences of performing similar tasks in the past. The third factor of personal and situation resources/constraints pertains to the assessment of the availability of different resources for performing specific tasks. We argue that MRIT (maturity and reach of Internet technologies) facilitates the analysis of task performance by individuals and overcomes personal and situational resources/constraints. Reliable Internet connections can ease people's concerns about the likelihood of interruption of online transactions before they are completed successfully. A sense of assurance about the security of Internet channel contributes to increased confidence that conducting online transactions do not involve financial and personal risks. Research shows that low levels of ICT diffusion can limit awareness about information and e-commerce technologies (Molla \& Licker, 2005a). Based on the foregoing discussion, the fourth hypothesis can be stated as:

Hypothesis 4: Maturity and reach of Internet technologies (MRIT) is positively related to, and is an antecedent of, technological and entrepreneurial efficacy (TEE).

\subsection{Uncertainty Avoidance (UA), Perceived Efficacy of Institutional Safety-Net (PEISN) and E-Commerce Adoption}

Diffusion of Innovation theory asserts that the rates of diffusion are dependent on the characteristics of the adopters, the social network, the communication, and the characteristics of the innovation and the promoters. The characteristics of the adopters within a particular homogeneous group may be reflected by certain traits. Hofstede (1980) defined culture as a "collective programming" of minds of people within a society. The apprehension that their sensitive information may be stolen and misused is a key reason why many consumers feel anxious in using e-commerce. Uncertainty avoidance, a sense of discomfort with vulnerability and/or uncertainty, is a cultural construct (Hofstede, 1980). Research shows that security, privacy, and fraud are significant concerns in the minds of e-commerce consumers (Aleid et al., 2009). Uncertainty avoidance is defined as "the extent of feeling threatened 
by uncertain or unknown situations" (Dorfman \& Howell, 1997). In countries with high uncertainty avoidance, individuals tend to minimize ambiguity because they feel anxious in uncertain situations (Hofstede, 1980). In contrast, people in countries with low uncertainty avoidance feel relatively more comfortable with uncertain situations and can tolerate different opinions and behaviors.

Several scholars have criticized using aggregate measures of cultural constructs published by Hofstede (1980) for assessing individual level differences among different cultures (Bearden et al., 2006; Lim et al., 2006; Zhao et al., 2014). However, Hofstede's (1980) measures are appropriate to use for country-level assessment of cultures. (Smith et al., 2013). Researchers from many disciplines have replicated Hofstede's empirical results and used his cultural dimensions (Akinduko et al., 2017; Hallikainen \& Laukkanen, 2018; Karahanna et al., 2013; Merhi, 2018; Merhi \& Ahluwalia, 2015; Merkin, 2006; Mladenović et al., 2017). Unlike studies that are at the individual level at which Hofstede measures are often criticized, this manuscript correctly utilizes Hofstede to do a national level data analysis.

Uncertainty avoidance was found to negatively impact consumers' buying decision on Internet (Lim et al., 2004) and adoption of technology products (Bagchi et al., 2003). Typically, e-commerce puts the purchasers in a weaker position relative to the sellers, therefore invoking unbalanced risks against purchasers. Some examples of risk perceptions faced by e-commerce consumers are: receiving a product different from one expected, not receiving a product at all even after payment is made, not receiving product when it was promised, and breach of personal and financial information. Hofstede (1980) argues that individuals in countries with high uncertainty avoidance values are generally less willing to accept personal risk than those in countries that have low uncertainty avoidance index. People in high uncertainty avoidance societies are expected to avoid risky behavior (Kahneman \& Tversky, 1979). Thus,

Hypothesis 5: Uncertainty avoidance is negatively related to, and is an antecedent of, e-commerce adoption.

Lyytinen and Damsgaard (2001) argue that the diffusion of innovation theory by itself is not adequate to explain the diffusion of information technologies in organizations because the technologies are subject to multiple forces, such as the influences of institutions, business context, and the economic and technological constraints. These forces, when exerting different pressures, can result in significant variations in diffusion of similar technologies. For example, considerable variations in the adoption of EDI technologies in Hong Kong, Denmark, and Finland were reported even though the motivations for the innovation were similar (Lyytinen \& Damsgaard, 2001). The effectiveness of institutions in regulating fair trade practices and protecting the rights of consumers are significant factors in enabling adoption of innovation. For example, protection from credit card fraud emboldens people to conduct online transactions. Research shows that in general, people perceive e-commerce as more risky than conventional commerce (Chiu et al., 2014; Brosdahl \& Almousa, 2013). Therefore, people's perceptions about the efficacy of institutions in delivering legitimate protection to them is an important determinant of e-commerce adoption. Presence of risk mitigating institutions can serve as coping mechanisms against perceived risks faced by consumers. Legal approach is the most common method of seeking justice; and effectiveness of laws is among the factors proposed in the CPT framework (Bajaj \& Leonard, 2004). However, in many countries, seeking legal remedies is expensive and takes a very long time. People need remedies that are swift and which they can trust. For example, most retail businesses in USA state their return policies encouraging consumers to purchase the products, even for "just trying them out." Safety nets is defined in Wordnet as "a guarantee of professional or financial security" (WordNet2.1, 2005). Safety nets are risk-shifting devices that are used in situations where normal-risks cannot be tolerated (Hovakimian et al., 2003). This paper draws from the safety-net literature to propose a new construct called Perceived Efficacy of Institutional Safety-Nets (PEISN) and empirically examines its relationship with e-commerce adoption. PEISN 
provides a sense of assurance that the online transactions are backed by institutions that are designed to safeguard consumers' interests by providing financial or professional guarantees.

As mentioned previously, PEISN is a perception about the effectiveness of safety nets that are hedging devices against risks associated with e-commerce. PEISN reflects people's assessment of the effectiveness of safety nets such as protection to buyers of online products and services. Uncertainty avoidance is also associated with risk; societies with greater uncertainty avoidance tend to minimize risks. Additionally, the societies with higher uncertainty avoidance prefer structured lives, and expect formal institutions to enforce stricter rules and laws covering most situations (House et al., 2004). Accordingly, people with higher uncertainty avoidance have lower acceptance of uncertainty and higher needs for structures, i.e. stronger formal rules and regulations (Lim et al., 2004). Consequently, people in societies with high uncertainty avoidance perceive a greater need for more effective safety nets, and they are likely to expect stricter standards for these institutions compared to people in societies with low uncertainty avoidance. Using the expectation disconfirmation principle (Oliver, 1977), the sixth hypothesis is now stated.

Hypothesis 6: Uncertainty avoidance (UA) is negatively related to, and is an antecedent of, perceived efficacy of institutional safety nets (PEISN).

Institutional safety nets such as efficient legal system protecting consumer rights can assuage the anxiousness of those who consider that online buying involve risks. Organizations like Better Business Bureau's (www.bbb.com) and TRUSTe (www.etrust.com) also provide structural assurances to customers by providing their reliability seals (Gefen et al., 2003). In a country where the legal systems are well developed, and enforcement mechanisms are efficient, individuals feel confident that their interests are protected. Research shows that potential and existing adopters of e-commerce are wary about consumer protection enforcement and laws governing e-commerce transactions (Aleid et al., 2009). People are reluctant to adopt an innovation unless they feel the confidence that their risks are contained (Kwast \& Passmore, 2000). Because effective safety nets mitigate risks, the seventh hypothesis posits that:

Hypothesis 7: Perceived efficacy of institutional safety-net (PEISN) is positively related to, and is an antecedent of, e-commerce adoption.

Figure 1 summarizes the discussion in this section by showing all seven hypothesized relationships.

\section{DATA}

Country level secondary data consisting of seventy countries formed the initial sample for conducting the empirical analysis of the hypothesized relationships. Because the determinants comprise of macrolevel indicators at the country-level, the sampling frame was formed by the data published by large, reputable organizations, which possess the wherewithal to collect data at a global scale. The data for GFIT, MRIT, TEE, and e-commerce adoption indexes were obtained from digital economy ranking study conducted by EIU (EIU, 2010). Table 2 shows different items comprising various indexes and their respective weights. The PEISN data is based on the survey items related to the effectiveness of ICT related regulatory environment and dispute resolution. These data are sourced from the "Executive Opinion Survey" of World Economic Forum (https://www.weforum.org/reports).

At this stage, data of 70 countries were available for further processing and analysis. The uncertainty avoidance index was drawn from the Hofstede cultural study (Hofstede, 1980; Hofstede et al., 2010). The uncertainty avoidance data for six of the seventy countries comprising the sampling frame was not available in the Hofstede's study, therefore separate procedures were adapted to impute 


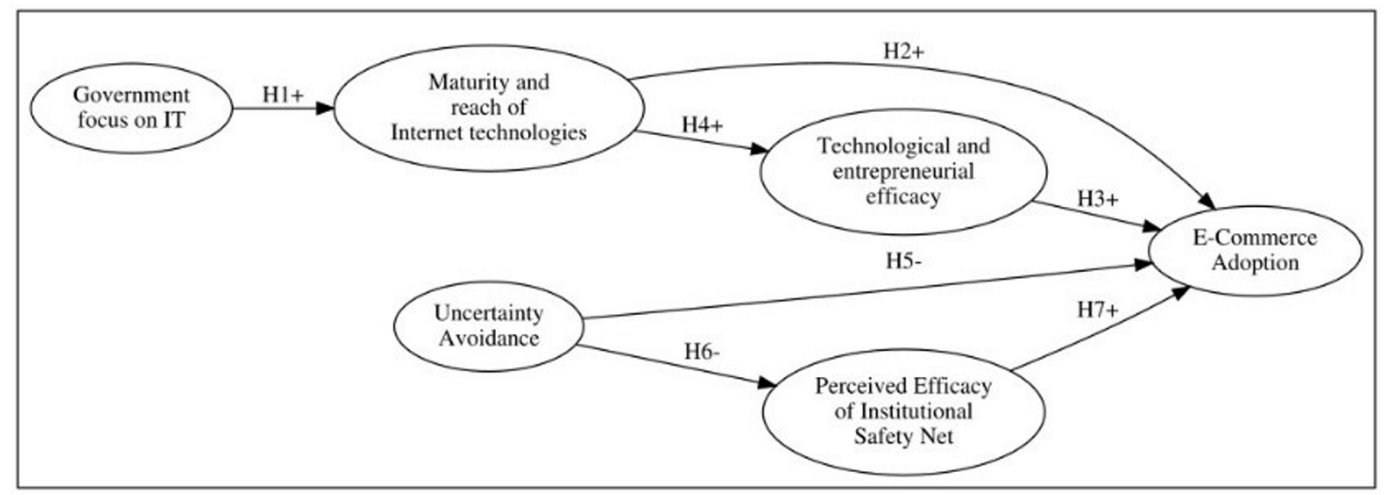

the missing data for these countries. The six countries were Ukraine, Lithuania, Latvia, Kazakhstan, Azerbaijan, and Bermuda. Uncertainty avoidance indexes for Ukraine, Lithuania, and Latvia were directly available at www.Hofstede-insights.com. Indexes for Kazakhstan and Azerbaijan were imputed by using two-step triangulation. We explain the triangulation method next. Several cultural studies have been conducted after the publication of Hofstede's study. In the first step, the countries whose uncertainty avoidance scores were available in Hofstede's and whose scores were nearly equal to those of Kazakhstan and Azerbaijan in different studies were identified (House et al., 2004; Kaasa, 2016). In the second step, the uncertainty avoidance scores in Hofstede's cultural index tables were determined for the equivalent countries and these index scores were substituted for the respective countries, namely, Kazakhstan and Azerbaijan. No tangible uncertainty avoidance score was found for Bermuda in the literature, therefore it was dropped from subsequent analysis, leaving 69 countries in the sampling frame. Table 3 shows the descriptive statistics of the data set.

\section{EMPIRICAL ANALYSIS AND DISCUSSION}

The hypothesized relationships were analyzed using partial least square modeling. The MatrixPLS package, a part of R statistical repository, was used to conduct the PLS analysis (Ronkk“ o, 2017). The analytic results were cross-validated by using the SmartPLS software.

We used PLS because we have formative and not reflective measures (Lowry \& Gaskin, 2014). Hair et al. (2017) offers rules of thumb for choosing between PLS-SEM and Covariance basedSEM. Hair et al. (2017) advise that it is best to use PLS-SEM when the data used in the analysis are secondary/archival, particularly single-item measures, and when the research objective is just to explain the relationships between exogenous and endogenous constructs. PLS-SEM is also the preferred method when sample size is below 100 and the constructs are formative (Hair et al., 2017). Our study meets all these criteria and we thus choose PLS-SEM.

The regression results of the bootstrapping analysis are shown in Table 4 . The standardized path coefficients of the hypothesized relationships and the $R^{2}$ values of the endogenous variables are shown in Figure 2. Except for the relationship between uncertainty avoidance and e-commerce adoption (H5), all other hypothesized relationships were found to be statistically significant. The results and their implications are discussed next.

According to the first hypothesis (H1), government's focus on IT (GFIT) is a significant antecedent of maturity and reach of Internet technologies (MRIT) in a country. The MRIT construct includes access, quality, cost, and security dimensions of the Internet technologies within a country. In the contemporary digital global economy, the implementation and execution of public policies strongly 
Table 2. Factor indexes

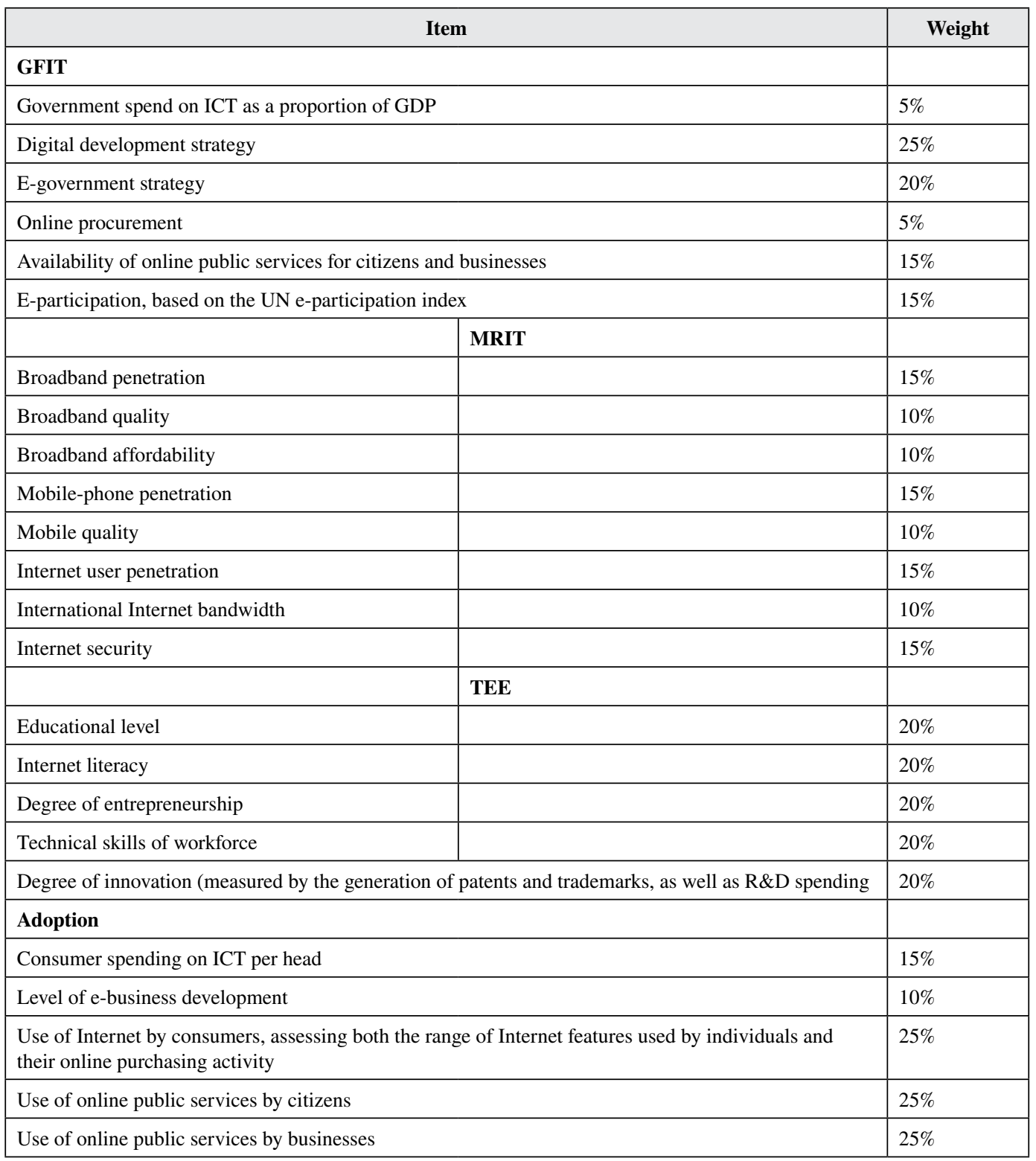

influence IT capabilities and environment (Bhattacherjee \& Sanford, 2006; Stoica et al., 2005). Many factors prompt increasing focus of governments on IT. This is because IT, directly and indirectly, is reported to contribute to the economic well-being of many countries (Van Dijk, 2003). Therefore, it is reasonable to expect that most governments would make conducive policies and work towards implementing and sustaining a robust IT infrastructure. Moreover, governments are expected to fulfill their fundamental responsibilities of framing and implementing policies for equitable participation of all stakeholders in the development and operation of IT infrastructure. Thus, government's involvement in diffusion of IT can be considered as a market regulator and as a provider of public good (Picot $\&$ Wernick, 2007). Governments are also direct beneficiaries from the affordances offered by IT 
Table 3. Descriptive statistics

\begin{tabular}{|l|l|l|l|l|l|l|}
\hline \multicolumn{1}{|c|}{ VAR } & \multicolumn{1}{c|}{$\mathbf{N}$} & \multicolumn{1}{c|}{ Mean } & \multicolumn{1}{c|}{ SD } & \multicolumn{1}{c|}{ Skew } & \multicolumn{1}{c|}{ Kurtosis } & \multicolumn{1}{c|}{ SE } \\
\hline GFIT & 69 & 6.26 & 1.89 & -0.08 & -1.06 & 0.23 \\
\hline MRIT & 69 & 5.13 & 1.96 & 0.03 & -1.47 & 0.24 \\
\hline TEE & 69 & 6.23 & 1.57 & -0.07 & -1.06 & 0.19 \\
\hline UA & 69 & 64.64 & 22.55 & -0.32 & -0.49 & 2.71 \\
\hline PEISN & 69 & 4.50 & 0.80 & -0.26 & -0.82 & 0.10 \\
\hline ADOPTION & 69 & 5.71 & 2.17 & -0.09 & -1.36 & 0.26 \\
\hline
\end{tabular}

Table 4. Summary results of the bootstrapping analysis

\begin{tabular}{|l|l|l|l|l|}
\hline \multicolumn{1}{|c|}{ Path } & \multicolumn{1}{c|}{ Estimate } & \multicolumn{1}{c|}{ SE } & \multicolumn{1}{c|}{ t } & \multicolumn{1}{c|}{ p } \\
\hline GFIT $\rightarrow$ MRIT & 0.86 & 0.02 & 35.86 & 0.00 \\
\hline MRIT $\rightarrow$ TEE & 0.91 & 0.02 & 50.67 & 0.00 \\
\hline MRIT $\rightarrow$ ADOPTION & 0.26 & 0.10 & 2.59 & 0.01 \\
\hline TEE $\rightarrow$ ADOPTION & 0.58 & 0.09 & 6.56 & 0.00 \\
\hline UA $\rightarrow$ PEISN & -0.29 & 0.12 & -2.48 & 0.02 \\
\hline UA $\rightarrow$ ADOPTION & -0.04 & 0.04 & -0.96 & 0.34 \\
\hline PEISN $\rightarrow$ ADOPTION & 0.16 & 0.06 & 2.87 & 0.01 \\
\hline
\end{tabular}

Figure 2. Path model

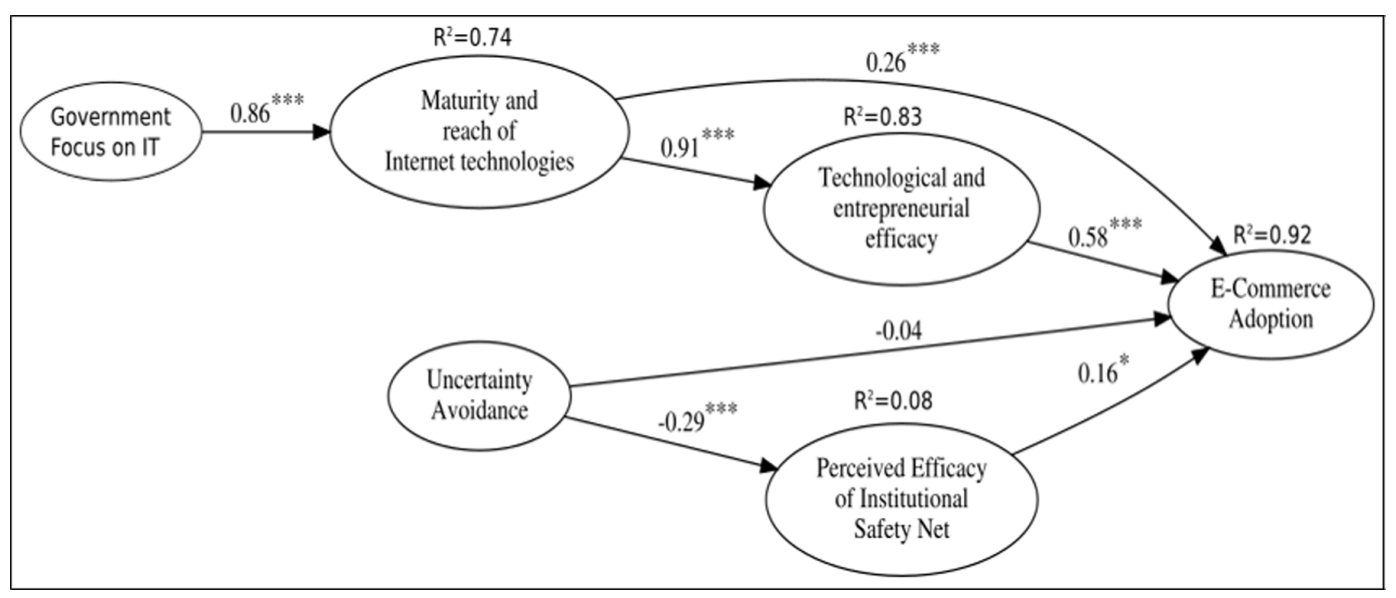

applications as they offer many of its services (e.g. e-tax) to citizens using digital platforms in order to reduce costs, improve speed, and empower people. The empirical results confirmed hypothesis one.

The second hypothesis postulated that greater MRIT results in greater adoption of e-commerce (H2). The MRIT construct includes technological factors (broadband and Internet user penetration) that are essential for sustaining electronic transactions. Other factors such as cost and quality promote usage. MRIT also includes the dimension of Internet security, which is an important factor in users' 
Table 5. Summary of hypotheses testing

\begin{tabular}{|c|c|c|}
\hline Label & Hypothesis & Confirmed? \\
\hline H1 & $\begin{array}{l}\text { Greater government's focus on IT (GFIT) positively affects the maturity and reach of } \\
\text { Internet technologies (MRIT) }\end{array}$ & Yes \\
\hline $\mathrm{H} 2 \mathrm{~A}$ & $\begin{array}{l}\text { Maturity and reach of Internet technologies (MRIT) positively affects e-commerce } \\
\text { adoption. }\end{array}$ & Yes \\
\hline $\mathrm{H} 2 \mathrm{~B}$ & $\begin{array}{l}\text { Maturity and reach of Internet technologies (MRIT) positively affects technological and } \\
\text { entrepreneurial efficacy (TEE). }\end{array}$ & Yes \\
\hline $\mathrm{H} 3$ & $\begin{array}{l}\text { Technological and entrepreneurial efficacy (TEE) positively affects ecommerce } \\
\text { adoption. }\end{array}$ & Yes \\
\hline $\mathrm{H} 4 \mathrm{~A}$ & Countries with greater uncertainty avoidance (UA) exhibit lower ecommerce adoption. & No \\
\hline $\mathrm{H} 4 \mathrm{~B}$ & $\begin{array}{l}\text { Countries with greater uncertainty avoidance (UA) exhibit lower perceived efficacy of } \\
\text { institutional safety-nets (PEISN) }\end{array}$ & Yes \\
\hline H5 & $\begin{array}{l}\text { Countries with greater perceived efficacy of institutional safety-nets } \\
\text { (PEISN) exhibit greater adoption of e-commerce }\end{array}$ & Yes $^{l}$ \\
\hline
\end{tabular}

${ }^{1}$ Supported at 0.1 level

adoption of e-commerce (Albrechtsen, 2007; Bones et al., 2007; Flavian \& Guinaliu, 2006). The results show that MRIT is a strong driver of e-commerce adoption.

Technological and entrepreneurial efficacy (TEE) taps into educational, technical, and Internet efficacy, and entrepreneurial factors. Perceived efficacy is one's confidence in the capacity to successfully complete a task (e.g. make an online purchase). Cognitive relational theory suggests that people form a sense about their capability to perform actions by appraising their environment (Lazarus \& Launier, 1978). Having access to the required technologies (i.e. broadband Internet, mobile wireless) at affordable cost and good quality (i.e. Internet security) lends confidence to the interested e-commerce users, thus augmenting their TEE. The results confirmed the positive relationship between MRIT and TEE.

TEE taps into educational and technical efficacy levels of people. Several studies have examined the role of efficacy in promoting use of IT at the individual level (Krueger \& Dickson, 1994; McElroy et al., 2007; McFarland, 2001; Thatcher \& Perrewe, 2002). Adequate confidence in security and quality of technologies is necessary before people feel assured to conduct e-commerce. This study also confirms the positive relationship between TEE and e-commerce adoption.

Uncertainty avoidance taps into the perception that people feel threatened by uncertain, unstructured situations, and ambiguity (Yoon, 2009). Individuals in countries with higher uncertainty avoidance index are more reluctant to engage with ambiguous situations (Hofstede, 1980). E-commerce transactions are characterized by presence of uncertainty because of spatial and temporal separation between buyers and sellers. This puts buyers in weaker positions compared to sellers, because in most cases, buyers complete their obligations before experiencing the purchased products. Therefore, societies with high uncertainty avoidance are likely to be deterred from using e-commerce. The data failed to confirm the direct relationship between UA and e-commerce adoption. This result is in consonance with the findings reported by the earlier studies that show that the main effect of UA on ecommerce adoption was not statistically significant (Lim et al., 2004). The results show that PEISN mediates the path between UA and e-commerce adoption. The data support this mediated relationship (H6).

The practical implication of this finding is that effective institutional mechanisms can mitigate the consequences of uncertainty avoidance. For example, governments can set up effective and easy to use risk lowering mechanisms that can expeditiously arbiter disputes arising from e-commerce transactions. Industries can device their own mechanisms that serve as deterrents for dishonest 
digital firms. For example, in USA, the Best Business Bureau allows consumers to file complaints against businesses and provide information to other consumers about the complaint-data. At the firm level, companies can clearly state and honor hassle free return policies and provide easy to use communication methods (i.e. telephone, email, mailing address) that consumers can use to seek help and request redress. Legal remedies in most countries, especially in developing countries, are expensive and take very long to complete. In many countries, the existing laws may have been designed in the context of non-digital commerce. Setting up effective institutions that can act as safety nets can encourage people to adopt e-commerce.

\section{CONCLUSION}

This study investigates the causes of country-level differences in e-commerce adoption by examining specific macro-level drivers of e-commerce adoption. PLS analytic procedure was used to confirm the hypothesized relationships. This study contributes to the literature in many ways. This paper proposes a rigorous causal model to assess inter-country adoption of e-commerce. The model is solidly grounded in theory, drawing from the relevant theories, namely: the stakeholder theory, the e-readiness model, the theory of planned behavior, the PEISN literature, and the CPT framework (Molla \& Licker, 2005a; Bajaj \& Leonard, 2004; Ajzen, 2002). Thus, the paper makes significant contributions to the literature, and also answers an important call for inter-country empirical research into e-commerce adoption (Tan et al., 2007). This paper makes an important contribution to practice by proposing that setting up effective risk lowering mechanisms may encourage people to adopt e-commerce, especially in societies with high uncertainty avoidance. Finally, by using a robust data set comprising 69 countries, the paper improves the generalizability of its findings. This is a substantial improvement over the existing literature, which is mostly based on one country or at most a comparison of a few countries.

The findings of this paper offer important implications for policy makers. The research model provides a diagnostic tool for policy makers and governments to find out which specific areas need more attention in advancing e-commerce adoption. The ability to transact digitally provides organizations and consumers with numerous advantages such as cost savings, greater deficiencies, faster time-to-completion, more efficient inventories and supply chain management (Uzoka, 2008; Zhu \& Thatcher, 2010). According to the findings of our study, policy makers need to consider their country's institutional and cultural environments. For instance, when people are reluctant to conduct Internet-based commercial transactions because of uncertainty avoidance, setting up effective safety nets can be beneficial in mitigating deterrent concerns of potential adopters. Industry and individual firms can device their own safety nets. The results show that government's role in implementing IT infrastructure in a country is a significant contributor to e-commerce adoption (total effect 0.68 ). The stakeholder theory explains different perspectives that the governments may take in implementing IT infrastructure in a country. In some countries, government owned organizations participate directly in ICT markets along with other private players (e.g. India); whereas in other countries governments confine their roles to policymaking and regulation (e.g. USA).

While this study makes many significant contributions to practice and research, its few limitations provide opportunities for further research on this important topic. Firstly, the findings are based on secondary data published by various organizations. Therefore, the findings reflect various indexes published by the source organizations. Studies of this nature have to depend on resourceful organizations such as the United Nations, ITU, EIU, and others for across countries data. Sourcing data from credible organizations lends integrity and authenticity to the findings. At the same time, the researchers are dependent on the composition of indexes and the times at which the data is made available by the sourcing organizations. For example, the cultural data published by Hofstede is several years old. The GLOBE cultural study (House et al., 2004) is more recent than the Hofstede study (Hofstede, 1980), but the data for this report was also collected prior to year 2000. A contemporary study comparable to Hofstede or GLOBE studies can provide updated scores of cultural factors. 
Moreover, data for all countries is not available in the Hofstede and the GLOBE studies. Therefore, uncertainty avoidance scores of five countries were substituted using other sources. We call upon additional research to examine inter-country adoption of e-commerce by improving these limitations. 


\section{REFERENCES}

Ajzen, I. (2002). Perceived behavioral control, self-efficacy, locus of control, and the theory of planned behavior. Journal of Applied Social Psychology, 32(4), 665-683. doi:10.1111/j.1559-1816.2002.tb00236.x

Akinduko, A., Ariwa, E., \& Gibson, M. (2017). A cross-cultural investigation into adoption of user controls in cyberstalking protection: A case study of Nigeria and the United Kingdom. In Innovative Computing Technology (INTECH), 2017 Seventh International Conference on (pp. 181-190). IEEE.

Al-Hudhaif, S., \& Alkubeyyer, A. (2011). E-commerce adoption factors in Saudi Arabia. International Journal of Business and Management, 6(9), 112-133. doi:10.5539/ijbm.v6n9p122

Al Kailani, M., \& Kumar, R. (2011). Investigating uncertainty avoidance and perceived risk for impacting Internet buying: A study in three national cultures. International Journal of Business and Management, 6(5), 76. doi:10.5539/ijbm.v6n5p76

Albrechtsen, E. (2007). A qualitative study of users' view on information security. Computers \& Security, 26(4), 276-289. doi:10.1016/j.cose.2006.11.004

Aleid, F., Rogerson, S., \& Fairweather, B. (2009). Factors affecting consumers adoption of ecommerce in Saudi Arabia from a consumers perspective. In IADIS International Conference e-Commerce (pp. 11-18). IADIS.

Bagchi, K., Cerveny, R., Hart, P., \& Peterson, M. (2003). The influence of national culture in information technology product adoption. In Proceedings of Americas Conference of Information Systems (pp. 957-965). Academic Press.

Bajaj, A., \& Leonard, L. N. (2004). The CPT framework: Understanding the roles of culture, policy and technology in promoting ecommerce readiness. Problems and Perspectives in Management, 2(3), 242-252.

Bandura, A. (1986). Social Foundations of Thought and Action: A Social Cognitive Theory. Englewood Cliffs, NJ: Prentice-Hall.

Bandura, A. (1997). Self-Efficacy: The Exercise of Control. New York, NY: Freeman.

Bearden, W. O., Money, R. B., \& Nevins, J. L. (2006). A measure of long-term orientation: Development and validation. Journal of the Academy of Marketing Science, 34(3), 456-467. doi:10.1177/0092070306286706

Belkhamza, Z., \& Wafa, S. A. (2014). The role of uncertainty avoidance on e-commerce acceptance across cultures. International Business Research, 7(5), 166-173. doi:10.5539/ibr.v7n5p166

Bhattacherjee, A. (2000). Acceptance of e-commerce services: The case of electronic brokerages. Systems, Man and Cybernetics, Part A: Systems and Humans. IEEE Transactions on, 30(4), 411-420.

Bhattacherjee, A., \& Sanford, C. (2006). Influence processes for information technology acceptance: An elaboration likelihood model. Management Information Systems Quarterly, 30(4), 805-825. doi:10.2307/25148755

Blažic, B. J., Jerman-Blažic, A., \& Arh, T. (2015). A virtual user community: Cultural backgrounds in the design of an internet-based service. Journal of Global Information Management, 23(2), 24-47. doi:10.4018/ JGIM.2015040102

Bones, E., Hasvold, P., Henriksen, E., \& Strandens, T. (2007). Risk analysis of information security in a mobile instant messaging and presence system for healthcare. International Journal of Medical Informatics, 76(9), 677-687. doi:10.1016/j.ijmedinf.2006.06.002 PMID:16931132

Bozeman, B. (2000). Technology transfer and public policy: A review of research and theory. Research Policy, 29(4), 627-655. doi:10.1016/S0048-7333(99)00093-1

Brosdahl, D. J., \& Almousa, M. (2013). Risk perception and internet shopping: Comparing united states and Saudi Arabian consumers. Journal of Management and Marketing Research, 13, 1-17.

Brousseau, E. (2003). E-commerce in France: Did early adoption prevent its development? The Information Society, 19(1), 45-57. doi:10.1080/01972240309473 
Calabrese, A., Capece, G., Di Pillo, F., \& Martino, F. (2014). Cultural adaptation of web design services as critical success factor for business excellence: A cross-cultural study of Portuguese, Brazilian, Angolan and Macanese Web sites. Cross Cultural Management, 21(2), 172-190. doi:10.1108/CCM-09-2012-0070

Chen, Y., \& Barnes, S. (2007). Initial trust and online buyer behavior. Industrial Management \& Data Systems, 107(1), 21-36. doi:10.1108/02635570710719034

Chen, Y., Chen, H., Huang, W., \& Ching, R. K. (2006). E-government strategies in developed and developing countries: An implementation framework and case study. Journal of Global Information Management, 14(1), 23-46. doi:10.4018/jgim.2006010102

Chiu, C. M., Wang, E. T., Fang, Y. H., \& Huang, H. Y. (2014). Understanding customers' repeat purchase intentions in b2c ecommerce: The roles of utilitarian value, hedonic value and perceived risk. Information Systems Journal, 24(1), 85-114. doi:10.1111/j.1365-2575.2012.00407.x

Choudrie, J., \& Dwivedi, Y. K. (2005). Investigating the research approached for examining technology adoption issues. Journal of Research Practice, 1(1), 1-11.

Commission, E. (2011). Online services, including e-commerce, in the single market. Retrieved from http:// ec.europa. eu/internal_market/e-commerce/docs/communication2012/SEC2011_1641_en.pdf

Cui, T., Wang, X., \& Teo, H. H. (2015). Building a culturally-competent Web site: A cross-cultural analysis of web site structure. Journal of Global Information Management, 23(4), 1-25. doi:10.4018/JGIM.2015100101

D’Onfro, J. (2015). Wal-Mart is losing the war against amazon. Available online at: http://www.businessinsider. com/wal-mart-ecommerce-vs-amazon-2015-7

Delone, W. H., \& Mclean, E. R. (2004). Measuring e-commerce success: Applying the Delone and Mclean information systems success model. International Journal of Electronic Commerce, 9(1), 31-47. doi:10.1080 /10864415.2004.11044317

Dorfman, P. W., Howell, J. P., Hibino, S., Lee, J. K., Tate, U., \& Bautista, A. (1997). Leadership in western and Asian countries: Commonalities and differences in effective leadership processes across cultures. The Leadership Quarterly, 8(3), 233-274. doi:10.1016/S1048-9843(97)90003-5

Edquid, R. (2017). 10 of the largest Ecommerce Markets in the World by Country. Available online at: https:// www.business.com/articles/10-of-the-largest-ecommerce-markets-in-the-world-b/

EIU. (2010). EIU: Digital economy rankings. Retrieved from http://graphics.eiu.com/upload/EIU_Digital_ economy_rankings_2010_FINAL_WEB.pdf

Elen, J., Clarebou, G., Sarfo, F. K., \& Louw, , J. P.-T., \& Stassens, N. (2010). Computer and information and communication technology: Students culture specific interpretations. Journal of Educational Technology \& Society, 13(4), 227-239.

EMarketer. (2016). Worldwide retail commerce sales: Emarketer's updates sales and forecast through 2019. Available online at: http://www.emarketer.com/FReport/ FWorldwide-Retail-Ecommerce-Sales-eMarketersUpdated-Estimates-Forecast-Through-2019/F2001716\&usg=AOvVaw2XRqmWRKUJ0kGEFY8c4wCQ

EUR. (2013). European e-commerce grew by 16\% to euro 363 billion in 2013, 2014. Available online at: http:// www.ecommerceeurope.eu/press/european-e-commerce-grew-by-16-to-363-billion-in-2013

Ferguson, C. W., \& Yen, D. C. (2006). A regional approach to e-commerce global expansion. International Journal of Electronic Business, 4(1), 99-114. doi:10.1504/IJEB.2006.009159

Flavian, C., \& Guinaliu, M. (2006). Consumer trust, perceived security and privacy policy. Industrial Management \& Data Systems, 106(5), 601-620. doi:10.1108/02635570610666403

Freeman, R. E., \& Reed, D. L. (1983). Stockholders and stakeholders: A new perspective on corporate governance. California Management Review, 25(3), 88-106. doi:10.2307/41165018

Gefen, D., Karahanna, E., \& Straub, D. W. (2003). Trust and TAM in online shopping: An integrated model. Management Information Systems Quarterly, 27(1), 51-90. doi:10.2307/30036519 
Ghose, A., \& Yao, Y. (2011). Using transaction prices to re-examine price dispersion in electronic markets. Information Systems Research, 22(2), 269-288. doi:10.1287/isre.1090.0252

Gist, M. E., \& Mitchell, T. R. (1992). Self-efficacy: A theoretical analysis of its determinants and malleability. Academy of Management Review, 17(2), 183-211. doi:10.5465/amr.1992.4279530

Govindaraju, R., \& Chandra, D. R. (2011). E-commerce adoption by Indonesian small, medium, and micro enterprises (SMMEs): Analysis of goals and barriers. In Communication Software and Networks (ICCSN), 2011 IEEE 3rd International Conference on (pp. 113-117). IEEE.

Grandon, E. E., Nasco, S. A., \& Mykytyn, P. P. Jr. (2011). Comparing theories to explain e-commerce adoption. Journal of Business Research, 64(3), 292-298. doi:10.1016/j.jbusres.2009.11.015

Hair, J., Hollingsworth, C. L., Randolph, A. B., \& Chong, A. Y. L. (2017). An updated and expanded assessment of PLS-SEM in information systems research. Industrial Management \& Data Systems, 117(3), 442-458. doi:10.1108/IMDS-04-2016-0130

Hallikainen, H., \& Laukkanen, T. (2018). National culture and consumer trust in e-commerce. International Journal of Information Management, 38(1), 97-106. doi:10.1016/j.ijinfomgt.2017.07.002

Ho, S.-C., Kauffman, R. J., \& Liang, T.-P. (2007). A growth theory perspective on b2c e-commerce growth in Europe: An exploratory study. Electronic Commerce Research and Applications, 6(3), 237-259. doi:10.1016/j. elerap.2006.06.003

Hofstede, G. (1980). Culture's consequences: International differences in work-related values. Beverly Hills, CA: Sage.

Hofstede, G., Hofstede, G. J., \& Minkov, M. (2010). Cultures and organizations: Software of the mind. London, UK: McGraw-Hill.

Hong, W., \& Zhu, K. (2006). Migrating to internet-based e-commerce: Factors affecting e-commerce adoption and migration at the firm level. Information \& Management, 43(2), 204-221. doi:10.1016/j.im.2005.06.003

House, R. J., Hanges, P. J., Javidan, M., Dorfman, P. W., \& Gupta, V. (2004). Culture, leadership, and organizations: The GLOBE study of 62 societies. Sage Publications.

Hovakimian, A., Kane, E. J., \& Laeven, L. (2003). How country and safety-net characteristics affect bank riskshifting. Journal of Financial Services Research, 23(3), 177-204. doi:10.1023/A:1024699811875

Hsu, M. H., \& Chiu, C. M. (2004). Internet self-efficacy and electronic service acceptance. Decision Support Systems, 38(3), 369-381. doi:10.1016/j.dss.2003.08.001

Javalgi, R., \& Ramsey, R. (2001). Strategic issues of e-commerce as an alternative global distribution system. International Marketing Review, 18(4), 376-391. doi:10.1108/02651330110398387

Jehangir, M., Dominic, P. D. D., Naseebullah, N., \& Khan, A. (2011). Towards digital economy: The development of ICT and e-commerce in Malaysia. Modern Applied Science, 5(2), 171. doi:10.5539/mas.v5n2p171

Kaasa, A. (2016). Culture as a possible factor of innovation: Evidence from the European union and neighboring countries. In Re-thinking Diversity (pp. 83-107). Springer. doi:10.1007/978-3-658-11502-9_5

Kaba, K., N'Da, B., Meso, P., \& Mbarika, V. W. (2009). Micro factors influencing the attitudes toward and the use of a mobile technology: A model of cell-phone use in guinea. IEEE Transactions on Professional Communication, 52(3), 272-290. doi:10.1109/TPC.2009.2025308

Kahneman, D., \& Tversky, A. (1979). Prospect theory: An analysis of decision under risk. Econometrica, 47(2), 263-291. doi:10.2307/1914185

Kalakota, R., \& Whinston, A. B. (1996). Electronic Commerce: A Manager's Guide. Reading, MA: AddisonWesley.

Karahanna, E., Williams, C. K., Polites, G. L., Liu, B., \& Seligman, L. (2013). Uncertainty avoidance and consumer perceptions of global e-commerce sites: A multi-level model. Drake Management Review, 3(1), 12-47.

Kaufman-Scarborough, C., \& Lindquist, J. D. (2002). E-shopping in a multiple channel environment. Journal of Consumer Marketing, 19(4), 333-350. doi:10.1108/07363760210433645 
Krueger, N., \& Dickson, P. (1994). How believing in ourselves increases risk taking: perceived self-efficacy and opportunity recognition. Decision Sciences, 25(3).

Kwast, M. L., \& Passmore, S. W. (2000). The subsidy provided by the federal safety net: Theory and evidence. In Financial Modernization and Regulation (pp. 35-55). Springer. doi:10.1007/978-1-4757-5228-1_4

Lazarus, R. S., \& Launier, R. (1978). Perspectives in Interactional Psychology. In Stress-related transactions between person and environment (pp. 287-327). New York: Springer. doi:10.1007/978-1-4613-3997-7_12

Lim, K., Sia, C., Lee, M., \& Ben, I. (2006). Do I trust you online, and if so, will I buy? An empirical study of two trust-building strategies. Journal of Management Information Systems, 23(2), 233-266. doi:10.2753/ MIS0742-1222230210

Lim, K. H., Leung, K., Sia, C. L., \& Lee, M. K. (2004). Is e-commerce boundary-less? effects of individualismcollectivism and uncertainty avoidance on internet shopping. Journal of International Business Studies, 35(6), 545-559. doi:10.1057/palgrave.jibs.8400104

Lowry, P. B., \& Gaskin, J. (2014). Partial least squares (PLS) structural equation modeling (SEM) for building and testing behavioral causal theory: When to choose it and how to use it. IEEE Transactions on Professional Communication, 57(2), 123-146. doi:10.1109/TPC.2014.2312452

Luo, J., Zhang, H., \& Li, H. (2007). Pricing strategy, online competition, and market dynamics in b2c electronic markets. In The First China Summer Workshop on Information Management (CSWIM 2007), (pp. 27-31). Institute of Operations Research and Management Sciences.

Lyytinen, K., \& Damsgaard, J. (2001). Whats wrong with the diffusion of innovation theory? In Diffusing software product and process innovations (pp. 173-190). Springer. doi:10.1007/978-0-387-35404-0_11

Mahmood, M. A., Bagchi, K., \& Ford, T. C. (2004). Online shopping behavior: Cross-country empirical research. International Journal of Electronic Commerce, 9(1), 9-30. doi:10.1080/10864415.2004.11044321

Mbarika, V. W. A., Okoli, C., Byrd, T. A., \& Datta, P. (2005). The neglected continent of is research: A research agenda for Sub-Saharan Africa. Journal of the Association for Information Systems, 6(5), 130-170. doi:10.17705/1jais.00067

McElroy, J. C., Hendrickson, A. R., Townsend, A. M., \& DeMarie, S. M. (2007). Dispositional factors in internet use: Personality versus cognitive style. Management Information Systems Quarterly, 31(4), 809-820. doi: $10.2307 / 25148821$

McFarland, D. J. (2001). The role of age and efficacy on technology acceptance: Implications for e-learning. World Conference on the $W W W$ and Internet Proceedings.

Merhi, M. I. (2018). Does national culture have any impact on e-government usage? International Journal of Technology Diffusion, 9(3), 29-45. doi:10.4018/IJTD.2018070103

Merhi, M. I., \& Ahluwalia, P. (2015). Country environments factors affecting e-commerce adoption: A crosscountry analysis. Journal of Management Systems, 25(3), 21-38.

Merhi, M. I., \& Ahluwalia, P. (2017). Influence of safety nets, uncertainty avoidance, and governments on e-commerce adoption: A country-level analysis. International Journal of Applied Business and Economic Research, 15(2), 397-408.

Merhi, M. I., \& Ahluwalia, P. (2018). Digital Economy and Corruption Perceptions: A Cross-Country Analysis. International Journal of Digital Accounting Research, 18(2), 29-47. doi:10.4192/1577-8517-v18_2

Merhi, M. I., \& Koong, K. S. (2013). E-government effectiveness: Assessment of contributing governments' ICT usage factors. International Journal of Business and Systems Research, 7(1), 1-24. doi:10.1504/ IJBSR.2013.050615

Merkin, R. (2006). Uncertainty Avoidance and the facework: A test of the Hofeste model. International Journal of Intercultural Relations, 30(2), 213-228. doi:10.1016/j.jintrel.2005.08.001

Mladenović, S. S., Mladenović, I., Milovančević, M., \& Denić, N. (2017). Cross-cultural dimensions influence on business internationalization by soft computing technique. Computers in Human Behavior, 75, 865-869. doi:10.1016/j.chb.2017.06.035 
Molla, A., \& Licker, P. S. (2005a). eCommerce adoption in developing countries: A model and instrument. Information \& Management, 42(6), 877-899. doi:10.1016/j.im.2004.09.002

Molla, A., \& Licker, P. S. (2005b). Perceived e-readiness factors in e-commerce adoption: An empirical investigation in a developing country. International Journal of Electronic Commerce, 10(1), 83-110. doi:10.1 080/10864415.2005.11043963

Okoli, C., Mbarika, V. W. A., \& McCoy, S. (2010). The effects of infrastructure and policy on e- business in Latin America and Sub-Saharan Africa. European Journal of Information Systems, 19(1), 5-20. doi:10.1057/ ejis. 2009.48

Oliver, R. L. (1977). Effect of expectation and disconfirmation on postexposure product evaluations: An alternative interpretation. The Journal of Applied Psychology, 62(4), 480-486. doi:10.1037/0021-9010.62.4.480

Papazafeiropoulou, A. (2004). Inter-country analysis of electronic commerce adoption in South Eastern Europe: Policy recommendations for the region. Journal of Global Information Technology Management, 7(2), 54-69. doi:10.1080/1097198X.2004.10856372

Papazafeiropoulou, A., \& Pouloudi, A. (2000). The government's role in improving electronic commerce adoption. ECIS 2000 Proceedings, 188.

Pavlou, P. A., \& Gefen, D. (2004). Building effective online marketplaces with institution-based trust. Information Systems Research, 15(1), 37-59. doi:10.1287/isre.1040.0015

Picot, A., \& Wernick, C. (2007). The role of government in broadband access. Telecommunications Policy, 31(10), 660-674. doi:10.1016/j.telpol.2007.08.002

Postnord. (2014). E-commerce in Europe 2014. Available online at: http://www.postnord.com/globalassets/ global/ english/document/publications/2014/e-commerce-in-europe-2014.pdf

Ronkko, M. (2017). Matrixpls: Matrix-based Partial Least Squares Estimation. R package version 1.0.5. Retrieved from https://github.com/mronkko/matrixpls

Rose, G., \& Straub, D. W. (2001). The effect of download time on consumer attitude toward the e-service retail. e-Service Journal, 3(1), 55-76. doi:10.2979/esj.2001.1.1.55

Smith, R., Deitz, G., Royne, M. B., Hansen, J. D., Grünhagen, M., \& Witte, C. (2013). Cross-cultural examination of online shopping behavior: A comparison of Norway, Germany, and the United States. Journal of Business Research, 66(3), 328-335. doi:10.1016/j.jbusres.2011.08.013

Stambor, Z. (2010). E-commerce will gradually emerge abroad, Forrester research predicts. Available online at: http://www.Internetretailer.com/2010/01/29/e-commerce-will-gradually-emerge-abroad-forrester-researchpredicts

Statista. (2017). E-commerce sales as percentage of total retail sales in selected countries in 2017. Available online at: https://www.statista.com/statistics/255083/online-sales-as-share-of-total-retail-sales-in-selected-countries/

Stoica, M., Miller, D. W., \& Stotlar, D. (2005). New technology adoption, business strategy and government involvement: The case of mobile commerce. Journal of Nonprofit \& Public Sector Marketing, 13(1/2), 213-232. doi:10.1300/J054v13n01_12

Stylianou, C., Robbins, S. S., \& Jackson, P. (2003). Perceptions and attitudes about e-commerce development in china: An exploratory study. Journal of Global Information Management, 11(2), 31-47. doi:10.4018/ jgim. 2003040102

Tan, J., Tyler, K., \& Manica, A. (2007). Business-to-business adoption of eCommerce in China. Information \& Management, 44(3), 332-351. doi:10.1016/j.im.2007.04.001

Thatcher, J. B., \& Perrewe, P. L. (2002). An empirical examination of individual traits as antecedents to computer anxiety and computer self-efficacy. Management Information Systems Quarterly, 26(4), 381-396. doi: $10.2307 / 4132314$

Tong, X. (2010). A cross-national investigation of an extended technology acceptance model in the online shopping context. International Journal of Retail \& Distribution Management, 38(10), 742-759. doi:10.1108/09590551011076524 
Treese, G. W., \& Stewart, L. C. (1998). Designing Systems for Internet Commerce. Reading, MA: Addison-Wesley.

Uzoka, F. (2008). Organizational influences on e-commerce adoption in a developing country context using UTAUT. International Journal of Business Information Systems, 3(3), 300-316. doi:10.1504/IJBIS.2008.017287

Van Dijk, M. P. (2003). Government policies with respect to an information technology cluster in Bangalore, India. European Journal of Development Research, 15(2), 93-108. doi:10.1080/09578810312331287495

Vyas, A., \& Gupta, S. (2017). Challenges Assessment for the E-Commerce Industry in India: A Review (With Special Reference to Flipkart V/S Snapdeal). Journal of Global Information Management, $25(4), 16-31$. doi:10.4018/JGIM.2017100102

Wang, V., Lou, H., Wang, Y., \& Guo, C. (2015). Differences in organizational Web site design across cultures: A comparative study of US and Chinese industrial SMEs. Asia Pacific Journal of Marketing and Logistics, 27(4), 582-599. doi:10.1108/APJML-07-2014-0116

Wong, P.-K. (2003). Global and national factors affecting e-commerce diffusion in Singapore. The Information Society, 19(1), 19-32. doi:10.1080/01972240309471

WordNet2.1. (2005). Wordnet: An electronic lexical database. Princeton University.

Wu, C. H., \& Tsai, S. B. (2018). Using DEMATEL-Based ANP Model to Measure the Successful Factors of E-Commerce. Journal of Global Information Management, 26(1), 120-135. doi:10.4018/JGIM.2018010107

Yoon, C. (2009). The effects of national culture values on consumer acceptance of e-commerce: Online shoppers in china. Information \& Management, 46(5), 294-301. doi:10.1016/j.im.2009.06.001

Zhao, F., Shen, K. N., \& Collier, A. (2014). Effects of national culture on e-government diffusion-A global study of 55 countries. Information \& Management, 51(8), 1005-1016. doi:10.1016/j.im.2014.06.004

Zhu, L., \& Thatcher, S. M. B. (2010). National information ecology: A new institutional economics perspective on global e-commerce adoption. Journal of Electronic Commerce Research, 11(1), 53-72.

Zwass, V. (1996). Electronic commerce: Structures and issues. International Journal of Electronic Commerce, 1(1), 3-23. doi:10.1080/10864415.1998.11518323

Zwick, D., \& Dholakia, N. (2008). Info transformation of markets: Introduction to the special issue on marketing and information technology. Journal of Macromarketing, 28(4), 318-325. doi:10.1177/0276146708325381

\section{ENDNOTE}

1 It was published before the PERM Model.

Punit Ahluwalia is currently an Associate Professor in the Information Systems department at the University of Texas-Rio Grande Valley. He received a Ph.D. in Computer Information Systems from Georgia State University, Atlanta in 2006. He also has graduate degrees in CIS from Georgia State University, and in Management and Systems from IIT-Delhi. His research interests include IT enabled empowerment, Impacts of digitization in Societies, and Information Security. He has authored numerous papers in many prestigious journal and conference papers.

Mohammad I. Merhi is a Department Chair and Associate Professor of Decision Sciences at the Judd Leighton School of Business \& Economics at Indiana University South Bend. His research interests include behavioral aspects of information security and privacy. Dr. Merhi is also interested in researching issues related to the design, adoption and implementation of information systems in organizations especially in the health and the government sectors. He is also interested in investigating technology adoption at the country-level. Dr. Merhi has published his research in several leading journals. He has also presented his research at leading international and national conference meetings and workshops. 